\title{
PENGARUH MEREK TERHADAP KEPUASAN PELANGGAN (STUDI KASUS : FURNITURE IMPOR B\&B ITALIA)
}

\author{
Margaretha Hillary \\ Program Studi Magister Manajemen Universitas Tarumanagara \\ hillary.komara@gmail.com
}

\begin{abstract}
The purpose of this research is to examine the effect of Brand which dimensions researched are Brand Image, Brand Equity, and Brand Personality, toward Customer Satisfaction. The population used for the research were users of B\&B Italia furniture and domiciled in DKI Jakarta. The sample size for this research were 100 respondents. Data used in this research are primary data obtained from online questionnaire and secondary data obtained from books and journals and purposive sampling techniques was employed to process all the data. The analytical techniques that are used in this research are composed of multiple regression analysis using the $t$ test, $F$ test, and the coefficient of determination $\left(R^{2}\right)$. Data processing is using the SPSS ver. 25.0 for Windows. The results of this research show that there is a significant influence between Brand Image $\left(\mathrm{X}_{1}\right)$ and Customer Satisfaction (Y) with the number of beta coefficient is 0.495 . There is also a significant influence between Brand Equity $\left(\mathrm{X}_{2}\right)$ and Customer Satisfaction (Y) with the number of beta coefficient is 0.241. And the last, there is a significant influence between Brand Personality $\left(\mathrm{X}_{3}\right)$ and Customer Satisfaction (Y) with the number of beta coefficient is 0.175 . Based on the coefficient of determination, the independent variables influenced by $60.1 \%$ toward the dependent variable and the rest is $39.9 \%$ was influenced by another variable which not investigated in this research.
\end{abstract}

Abstrak : Penelitian ini bertujuan untuk mengetahui pengaruh Merek dimana dimensi yang diteliti adalah Citra Merek, Ekuitas Merek, dan Kepribadian Merek, terhadap Kepuasan Pelanggan. Populasi yang digunakan untuk penelitian adalah pengguna furniture B\&B Italia yang berdomisili di DKI Jakarta. Ukuran sampel untuk penelitian ini berjumlah 100 responden. Data yang digunakan dalam penelitian ini adalah data primer yang diperoleh dari kuesioner online dan data sekunder yang diperoleh dari buku-buku dan jurnal dan teknik purposive sampling diterapkan untuk memproses semua data. Teknik analisis yang digunakan dalam penelitian ini adalah komposisi dari analisis regresi berganda serta menggunakan uji t, uji F, dan koefisien determinasi $\left(\mathrm{R}^{2}\right)$. Data diproses menggunakan SPSS versi 25.0 untuk Windows. Hasil dari penelitian menunjukkan bahwa terdapat pengaruh signifikan antara Citra Merek $\left(\mathrm{X}_{1}\right)$ dan Kepuasan Pelanggan (Y) dengan nilai koefisien beta sebesar 0,495. Terdapat pula pengaruh signifikan antara Ekuitas Merek $\left(\mathrm{X}_{2}\right)$ dan Kepuasan Pelanggan (Y) dengan nilai koefisien beta sebesar 0,241. Terakhir, terdapat pengaruh signifikan antara Kepribadian Merek $\left(\mathrm{X}_{3}\right)$ dan Kepuasan Pelanggan (Y) dengan nilai koefisien beta sebesar 0,175. Berdasarkan koefisien determinasi, variabel independen berpengaruh sebesar 60,1\% terhadap variabel dependen dan sisanya sebesar 39,9\% dipengaruhi oleh variabel lain yang tidak termasuk dalam penelitian ini.

Keywords : Brand Image, Brand Equity, Brand Personality, Customer Satisfaction

\section{PENDAHULUAN}

Memuaskan kebutuhan konsumen adalah salah satu prinsip yang diterapkan oleh setiap perusahaan. Menurut Tjiptono (1997, p.24), “terciptanya kepuasan pelanggan dapat memberikan berbagai manfaat, di antaranya hubungan perusahaan dengan pelanggan menjadi harmonis, memberikan dasar yang baik bagi pembelian ulang dan terciptanya loyalitas pelanggan dan memberikan rekomendasi dari mulut-ke-mulut (word-of-mouth) yang 
menguntungkan bagi perusahaan". Hal ini berarti kepuasan merupakan salah satu faktor kunci bagi konsumen dalam volume keberlangsungan suatu perusahaan. Menurut Kotler dan Keller (2014, p.128), "kepuasan adalah tingkat perasaan seseorang setelah membandingkan kinerja (hasil) yang dia rasakan dengan harapannya". Oleh karena itu, perusahaan dituntut untuk dapat menciptakan suatu keunikan tersendiri diiringi penanaman citra yang positif terhadap produk yang dimiliki agar bisa unggul di antara para pesaing. Suatu produk menjadi berbeda karena adanya merek.

Menurut Southgate yang dikuti oleh Rangkuti (2008, p.19) dalam bukunya, merek yang baik tidak harus yang dapat menampilkan nilai fungsionalnya, melainkan juga yang dapat memberikan nilai tertentu dalam benak konsumen. Oleh karena itu, citra merek yang kuat akan mendorong terciptanya merek yang kuat pula. Dalam kepribadian merek tertentu, konsumen dengan karakter kepribadian yang berbeda-beda akan tertarik dan kemudian akan mengembangkan preferensi akan sebuah merek lebih lanjut. Sebuah merek memiliki ekuitas merek yang positif ketika konsumen lebih menyukai satu merek dibanding merek lain dalam kategori produk yang sama, begitu pula sebaliknya. Berdasarkan pernyataan-pernyataan tersebut, terdapat dugaan kuat bahwa ketika sebuah perusahaan memberikan merek yang kuat pada saat itu merek akan dapat memberikan kepuasan dan timbul loyalitas merek apabila konsumen juga akan membeli di lain waktu, begitu pula bila perusahaan ingin meningkatkan kepuasan, perusahaan harus dapat membangun sebuah merek yang kuat.

B\&B Italia adalah sebuah perusahaan Itali yang memimpin dalam dunia desain furniture secara internasional. Untuk memperluas pangsa pasarnya di Indonesia, B\&B Italia bekerja sama dengan Magran sebagai distributor eksklusif B\&B Italia di Indonesia. Dengan meningkatnya perkembangan industri mebel lokal di Indonesia sebesar 7\% pada tahun 2019 dibanding tahun sebelumnya, B\&B Italia sebagai salah satu merek internasional harus dapat mempertahankan pangsa pasarnya agar tidak 'termakan' oleh merek lokal. Karena segmentasi perusahaan yang ditujukan untuk kalangan menengah-ke-atas dimana skala kalangan tersebut tidak terlalu luas, B\&B Italia harus dapat memuaskan pelanggan agar pelanggan tersebut dapat melakukan pembelian ulang atau berbagi pengalaman kepada pelanggan lainnya.

\section{Tujuan Penelitian}

Tujuan penelitian pada subjek ini adalah :

1. Untuk mengetahui apakah terdapat pengaruh citra merek terhadap kepuasan pelanggan furniture impor B\&B Italia.

2. Untuk mengetahui apakah terdapat pengaruh ekuitas merek terhadap kepuasan pelanggan furniture impor B\&B Italia/

3. Untuk mengetahui apakah terdapat pengaruh kepribadian merek terhadap kepuasan pelanggan furniture impor B\&B Italia.

4. Untuk mengetahui apakah terdapat pengaruh citra merek, ekuitas merek, dan kepribadian merek secara simultan terhadap kepuasan pelanggan furniture impor B\&B Italia.

\section{TELAAH KEPUSTAKAAN Merek (Brand)}

Menurut American Marketing Association (Kotler \& Keller, 2014, p.112), definisi merek adalah "nama, istilah, tanda, lambang, atau desain, atau kombinasinya, yang dimaksudkan untuk mengidetifikasikan barang atau jasa dari salah satu penjual atau kelompok penjual dan mendiferensiasikan mereka dari para pesaing". Susanto dan Wijanarko (2004, p.4) menyatakan bahwa merek adalah nama atau simbol yang diasosiasikan dengan produk atau jasa akan menimbulkan arti psikologis atau asosiasi.

\section{Citra Merek (Brand Image)}

Supranto dan Limakrisna (2007, p.132) menyatakan citra merek adalah apa yang konsumen pikir dan rasakan ketika mendengar atau melihat suatu merek dan apa yang 
konsumen pelajari tentang merek. Menurut Tjiptono (2011, p.112), "citra merek adalah deskripsi tentang asosiasi dan keyakinan konsumen terhadap merek tertentu. Citra merek adalah pengamatan dan kepercayaan yang digenggam konsumen, seperti yang dicerminkan di asosiasi atau di ingatan konsumen". Citra merek dapat dilihat dari beberapa hal sebagai berikut (Kotler \& Keller, 2014, p.347):

1. Keunggulan asosiasi merek, merupakan salah satu faktor pembentuk citra merek, dimana produk tersebut unggul dalam persaingan.

2. Kekuatan asosiasi merek, bagaimana informasi masuk ke dalam ingatan konsumen dan bagaimana proses bertahan sebagai bagian dari citra merek.

3. Keunikan asosiasi merek, harus diciptakan keunikan dibanding dengan merek-merek lain yang dapat dijadikan alasan bagi konsumen untuk memilih suatu merek tertentu.

\section{Ekuitas Merek (Brand Equity)}

Menurut Kotler dan Keller (2014, p.263), ekuitas merek adalah nilai tambah yang diberikan para produk dan jasa. Ekuitas merek dapat tercermin dalam cara konsumen berpikir, merasa, dan bertindak dalam hubungannya dengan merek, dan juga harga, pangsa pasar, dan profitabilitas yang diberikan merek bagi perusahaan. Menurut Aaker (1996, p.10-25), terdapat lima komponen pada ekuitas merek yaitu:

1. Kesadaran Merek (Brand Awareness), yaitu kemampuan konsumen untuk mengenali atau mengingat kembali bahwa suatu merek merupakan bagian dari kategori produk tertentu.

2. Asosiasi Merek (Brand Association), adalah segala sesuatu yang terkait dengan memori terhadap sebuah merek.

3. Persepsi Kualitas (Perceived Quality), adalah penilaian konsumen terhadap keseluruhan kualitas atau keunggulan suatu produk.

4. Loyalitas Merek (Brand Loyalty), menunjukkan pola pembelian yang konsisten terhadap merek sepanjang waktu dan juga sikap menyenangkan terhadap sebuah merek.

5. Aset-aset lain yang berkaitan dengan merek (Other Brand-related Assets).

\section{Kepribadian Merek (Brand Personality)}

Aaker (1996, p.141) mendefinisikan kepribadian merek sebagai "sekumpulan karakteristik manusia yang dikaitkan atau dihubungkan dengan merek". Sedangkan Kotler dan Keller (2014, p.167) dengan makna yang sama mengartikan kepribadian merek sebagai "campuran sifat manusia tertentu yang dapat dihubungkan dengan merek tertentu".

Kepribadian merek dapat membantu mengidentifikasi perbedaan kebutuhan walaupun dalam pasar yang sama. Pertama, kepribadian dapat membuat suatu merek menjadi lebih menarik dan mudah dikenali. Merek tanpa kepribadian akan sulit dikenali oleh pelanggan, terutama pada saat membangun hubungan dengan pelanggan. Kedua, kepribadian merek membantu memberikan pertimbangan atas gagasan untuk membantu merek. Ketiga, kepribadian merek dapat membantu mempererat hubungan merek dengan pelanggan, seperti layaknya teman atau penasihat (Surachman, 2008, p.26). Untuk mengukur kepribadian merek, digunakan Brand Personality Trait yang memiliki dimensi sebagai berikut (Aaker, 1997, p.348; Kotler \& Armstrong, 2010, p.140):

1. Sincerity (ketulusan), yang terdiri dari subdimensi seperti down to earth (rendah hati), honest (jujur), wholesome (sederhana), dan cheerful (gembira).

2. Excitement (semangat), yang terdiri dari subdimensi seperti daring (berani), spirited (semangat), imaginative (penuh imajinasi), dan up to date (modern).

3. Competence (kemampuan), yang terdiri dari subdimensi seperti reliable (andal), intelligent (pandai), dan successful (sukses).

4. Sophistication (keduniawian), yang terdiri dari subdimensi yaitu upper class (berkelas) dan charming (menarik).

5. Rugedness (ketangguhan), yang terdiri dari subdimensi yaitu outdoorsy (terbuka) dan tough (tangguh). 


\section{Kepuasan Pelanggan (Customer Satisfaction)}

Menurut Irawan (2008, p.3), kepuasan pelanggan adalah hasil akumulasi dari konsumen atau pelanggan dalam menggunakan produk dan jasa. Faktor-faktor yang mendorong kepuasan pelanggan adalah sebagai berikut (Irawan, 2008, p.37-39):

1. Kualitas produk, pelanggan puas bila setelah membeli dan menggunakan produk tersebut, ternyata kualitas produknya baik.

2. Harga, untuk pelanggan yang sensitif, harga murah adalah sumber kepuasan yang penting karena mereka akan mendapatkan value for money yang tinggi.

3. Service Quality (kualitas pelayanan), sangat bergantung pada tiga hal, yaitu sistem, teknologi, dan manusia.

4. Emotional Factor (faktor emosional), kepuasan pelanggan dapat timbul pada saat menggunakan produk yang memiliki brand image yang baik. Pelanggan akan merasa puas karena adanya emotional value (nilai emosional) yang diberikan oleh brand pada produk tertentu.

5. Biaya dan kemudahan, pelanggan akan semakin puas, apabila relatif mudah, nyaman, dan efisien dalam mendapatkan produk dan pelayanan.

Setiap industri dan produk memiliki angka kualitas yang berbeda-beda. Bagaimana bila terdapat lebih dari dua merek yang memiliki kualitas produk yang hampir sama? Menurut Irawan (2008, p.84), sebuah merek yang kuat kemudian akan menawarkan faktor emosional. Emotional factor dapat dibagi menjadi tiga dimensi (Irawan, 2008, p.83-89):

1. Estetika, aspek estetika pertama adalah bentuk yang dapat meliputi besar kecilnya, bentuk sudut, proporsi, dan kesimetrisan. Aspek estetika lain adalah warna.

2. Self-expressive Value (Nilai yang mengekspresikan individual), adalah kepuasan yang timbul karena lingkungan sosial di sekitarnya. Sebuah merek yang kuat dapat membuat seseorang melakukan pemilihan merek berdasarkan pertimbangan bagaimana orang lain akan melihat dia ketika menggunakan produk dari merek tersebut.

3. Brand Personality (Kepribadian merek), karakter yang jelas pada merek dapat memperngaruhi kepuasan pelanggannya.

\section{Hubungan Citra Merek, Ekuitas Merek, dan Kepribadian Merek dengan Kepuasan Pelanggan}

Irawan (2008, p.3) mendefinisikan kepuasan sebagai persepsi terhadap produk atau jasa yang telah memenuhi harapannya. Citra merek berkaitan erat dengan emosional konsumen atau nilai awal yang didapat oleh konsumen. Apabila produk atau jasa yang digunakan oleh konsumen ternyata sesuai dengan citra merek positif yang dibangun, maka konsumen tersebut dapat mengalami kepuasan. Ekuitas merek dapat menambah atau mengurangi nilai merek bagi konsumen. Sama halnya dengan citra merek, apabila konsumen dapat memberikan nilai yang positif pada merek dan ketika melakukan pembelian ternyata produk atau merek tersebut dapat memberikan nilai yang sesuai dengan konsumen, ada kemungkinan konsumen akan mengalami kepuasan. Konsumen cenderung memilih produk dengan kepribadian yang cocok dengan citra dirinya. Sehingga apabila konsumen melakukan pembelian yang ternyata kepribadian merek tersebut cocok dengan citra dirinya, maka ada kemungkinan konsumen dapat merasakan kepuasan.

\section{METODOLOGI PENELITIAN}

Jenis penelitian yang digunakan dalam penelitian ini adalah penelitian deskriptif, serta menggunakan pendekatan kuantitatif. Metode pengumpulan data yang digunakan adalah metode survei, yang mengambil sampel satu populasi dan menggunakan kuesioner sebagai alat pengumpulan data primer. Kuesioner yang disebar menggunakan skala Likert sebagai pengukuran atas jawaban akan pernyataan yang telah disediakan. Populasi penelitian adalah seluruh masyarakat di wilayah DKI Jakarta yang pernah membeli dan menggunakan furniture impor B\&B Italia. Peneliti menggunakn teknik purposive sampling. Jumlah sampel yang akan 
diteliti dalam penelitian ini ditetapkan sebanyak 100 responden. Metode-metode analisis yang digunakan pada penelitian ini adalah teknik uji validitas dan reliabilitas, uji asumsi klasik yang terdiri dari uji normalitas, uji multikolinearitas, dan uji heterokedastisitas, analisis regresi berganda, dan teknik pengujian hipotesis yang terdiri dari uji parsial (uji t), uji signifikan simultan (uji F), dan koefisien determinasi $\left(\mathrm{R}^{2}\right)$. Data diproses dengan menggunakan SPSS ver. 25.0 untuk Windows.

\section{ANALISIS DAN BAHASAN TEMUAN \\ Pembahasan}

Berdasarkan hasil pengujian validitas dan reliabilitas, diketahui bahwa semua variabel yang diuji bersifat valid dan reliabel. Setelah melalui uji validitas dan reliabilitas, data kemudian dianalisis menggunakan uji asumsi klasik terhadap model regresi yang terdiri dari uji normalitas, uji multikolinearitas, dan uji heteroskedastisitas. Berdasarkan ketiga uji asumsi klasik tersebut, diketahui model regresi dapat digunakan karena telah sesuai dengan persyaratan yaitu: 1) residual terdistribusi secara normal, 2) tidak terdapatnya gelaja multikolinearitas, dan 3) tidak terjadi heteroskedastisitas.

Dalam melakukan analisis regresi berganda, dirumuskan persamaan regresi sebagai berikut: $\mathrm{KP}=0,377+0,495(\mathrm{CM})+0,241(\mathrm{EM})+0,175(\mathrm{KM})$. Dimana KP merupakan variabel dependen yaitu Kepuasan Pelanggan (Y) dan variabel independen yang terdiri dari CM adalah Citra Merek $\left(\mathrm{X}_{1}\right)$, EM adalah Ekuitas Merek $\left(\mathrm{X}_{2}\right)$, dan $\mathrm{KM}$ adalah Kepribadian Merek $\left(\mathrm{X}_{3}\right)$. Setelah mendapatkan rumus persamaan regresi, selanjutnya dilakukanlah pengujian hipotesis berupa uji t, uji F, dan uji koefisien determinasi $\left(\mathrm{R}^{2}\right)$.

Hasil pengujian hipotesis pertama menunjukkan bahwa terdapat pengaruh positif dan signifikan citra merek terhadap kepuasan pelanggan. Hal ini diketahui dari hasil pengujian yang menunjukkan nilai signifikan citra merek $0,000<0,05$ dan nilai koefisien beta positif 0,495 . Hasil pengujian hipotesis kedua menunjukkan bahwa terdapat pengaruh positif dan signifikan ekuitas merek terhadap kepuasan pelanggan. Hal ini diketahui dari hasil pengujian yang menunjukkan ekuitas merek memiliki nilai koefisien beta positif 0,241 dan nilai signifikan $0,008<0,05$. Hasil pengujian hipotesis ketiga menunjukkan bahwa terdapat pengaruh positif dan signifikan kepribadian merek terhadap kepuasan pelanggan. Hal ini diketahui dari hasil pengujian yang menunjukkan kepribadian merek memiliki nilai signifikan 0,044 < 0,05 dan nilai koefisien beta positif 0,175 .

Hasil pengujian hipotesis keempat menunjukkan bahwa citra merek, ekuitas merek, dan kepribadian merek secara simultan memiliki pengaruh positif dan signifikan terhadap kepuasan pelanggan. Hal ini diketahui dari hasil pengujian $\mathrm{F}$ sebesar 48,265 > F tabel 2,70 dan nilai signifikan $0,000<0,05$. Hasil pengujian koefisien determinasi dalam penelitian ini adalah $60,1 \%$ yang menyatakan besarnya hubungan variabel independen terhadap variabel dependen. Sedangkan sisanya 39,9\% merupakan hubungan dengan variabel lain yang tidak termasuk dalam permodelan.

\section{KESIMPULAN DAN SARAN Kesimpulan}

1. Penelitian ini membuktikan adanya pengaruh positif dan signifikan antara citra merek terhadap kepuasan pelanggan furniture impor B\&B Italia.

2. Penelitian ini membuktikan adanya pengaruh positif dan signifikan antara ekuitas merek terhadap kepuasan pelanggan furniture impor B\&B Italia.

3. Penelitian ini membuktikan adanya pengaruh positif dan signifikan antara kepribadian merek terhadap kepuasan pelanggan furniture impor B\&B Italia.

4. Penelitian ini membuktikan adanya pengaruh positif dan signifikan antara citra merek, ekuitas merek, dan kepribadian merek secara simultan terhadap kepuasan pelanggan furniture impor B\&B Italia. 
5. Untuk meningkatkan kepuasan pelanggan, faktor citra merek, ekuitas merek, dan kepribadian merek harus diperhatikan dan ditingkatkan agar mendapat kepuasan yang maksimal.

\section{Saran}

1. Bagi perusahaan

a. Perusahaan harus lebih memperhatikan faktor citra merek, ekuitas merek, dan kepribadian merek dalam melakukan pemasaran produk B\&B Italia.

b. Perusahaan dapat meningkatkan citra merek dengan menjaga reputasi yang baik dalam melakukan pelayanan atau menjaga kualitas produk.

c. Perusahaan dapat meningkatkan ekuitas merek dengan event atau menjadi sponsor dalam kegiatan yang banyak menjaring desainer.

d. Perusahaan dapat menyampaikan kepribadian merek dengan pengulangan pesan kepribadian pada merek.

2. Bagi penelitian selanjutnya

a. Dapat mereplikasi penelitian ini dengan objek yang berbeda.

b. Untuk mencoba variabel-variabel lain yang diperkirakan dapat mempengaruhi kepuasan pelanggan.

\section{DAFTAR KEPUSTAKAAN}

Aaker, David. (1996). Building Strong Brands. New York : The Free Press

Aaker, Jennifer. (1997). Dimensions of Brand Personality. Journal of Marketing, 34 (3), 347356

Irawan, Handi. (2008). 10 Prinsip Kepuasan Pelanggan. Jakarta : Elex Media Komputindo

Kotler, P. \& Armstrong G. (2010). Prinsip-Prinsip Pemasaran (12 ${ }^{\text {th }}$ ed.). Jilid 1 \& 2. Jakarta : Erlangga

Kotler, P. \& Keller K.L. (2014). Manajemen Pemasaran (14 ${ }^{\text {th }}$ ed.). Jilid 1 \& 2. Jakarta : Erlangga

Rangkuti, Freddy. (2008). The Power of Brands. Jakarta : PT. Gramedia Pustaka Utama

Supranto, J. \& Nandan Limakrina. (2007). Perilaku Konsumen dan Strategi Pemasaran Untuk Memenangkan Persaingan Bisnis. Jakarta : Penerbit Mitra Wacana Media

Surachman, S.A. (2008). Dasar-Dasar Manajemen Merek (Alat Pemasaran Untuk Memenangkan Persaingan). Malang : Bayumedia Publishing

Susanto \& Hilmawan Wijanarko. (2004). Power Branding : Membangun Merek Unggul dan Organisasi Pendukungnya. Jakarta : PT. Mizan Publika Jakarta

Tjiptono, Fandy. (1997). Strategi Pemasaran (1 ${ }^{\text {st }}$ ed.). Yogyakarta : Penerbit Andi

Tjiptono, Fandy. (2011). Manajemen dan Strategi Merek. Yogyakarta : Penerbit Andi 